EFOMP Policy Statement

\title{
The European federation of organisations for medical physics policy statement no. 15: Recommended guidelines on the role of the medical physicist within the hospital governance board ${ }^{\text {ir }}$
}

\author{
Stelios Christofides ${ }^{\text {a, }}$, , Peter Sharp ${ }^{\text {b }}$ \\ ${ }^{a}$ Biomedical Research Foundation, P.O. Box 24039, 1700 Nicosia, Cyprus \\ ${ }^{\mathrm{b}}$ Department of Biomedical Physics and Bioengineering, Foresterhill, Aberdeen AB25 2ZD, UK
}

\section{A R T I C L E I N F O}

\section{Article history:}

Available online 19 February 2015

\section{Keywords:}

Hospital governance board

Medical physicist

Policy making

Strategic decisions

\begin{abstract}
A B S T R A C T
This EFOMP Policy Statement presents an outline on hospital governance and encourages the participation of the Medical Physicist in the hospital governance. It also emphasises how essential it is for Medical Physicists to engage in their hospital's governing board's committees for the overall good of the patient. (C) 2015 Associazione Italiana di Fisica Medica. Published by Elsevier Ltd. All rights reserved.
\end{abstract}

\section{Background}

Governance is an integral part of every organisation's improvement and advocacy efforts. Hospital representatives are challenged with providing insight and guidance on both on-going and emerging issues - including healthcare reform and cost containment, quality and patient safety, and workforce development.

\section{Governance board roles}

Governance boards have 3 primary roles [1]:

- to establish policies,

- to make significant and strategic decisions, and

- to oversee the organization's activity

\section{Policy making}

Effective execution of policy is necessary to fulfil the other two roles. Policies define focus and differentiate responsibilities among the board, the management, medical staff, other healthcare

\footnotetext{
Disclaimer Note: EFOMP Policy statement No.15 has been approved by EFOMP Council through postal ballot on the $30^{\text {th }}$ of November 2014 . Hence this paper has not been subjected to standard peer review, being an official policy statement of the European Federation of Organisations for Medical Physics.

* Corresponding author. Tel.: +357 22322 278; fax: +357 22325415.

E-mail address: c4stelios@gmail.com (S. Christofides).
}

professionals and other staff. Well-written policies lead to more efficient board functioning. Instead of having the same matter or very similar matters on the agenda repeatedly, the board can develop a policy that covers the issue and leave implementation of the policy to management. Governance boards have few meetings each year and it is essential to use that time wisely. At the same time, board-level policies should be reviewed at least annually to see if they are still needed or require updating.

\section{Decision making}

Boards make decisions about the organisation's vision, mission, and strategies and make choices that are strategic and significant. As decision makers, boards can also delegate non-governance type of decisions to others, such as the hospital management or administration. At the core of decision making a common culture of positive values and methods should be shared together with a common positive safety culture [2].

\section{Oversight}

Oversight is an important function, and governance boards are there to oversee, not to manage. Nevertheless, the board is legally responsible for everything that happens within the hospital, whether in the emergency department, a clinic, or a nursing unit. The board should set the tone by stating that the organisation's core value is to put patients first, it is committed to protect patients from avoidable harm and it will be open and honest with patients. In the 
area of quality, for example, the board may state that the organisation is committed to quality; establishing policies related to quality, such as clinical audit; ensuring that mechanisms are in place, such as committees, to establish a plan for quality; and monitoring implementation of the plan.

Board committees play an important role in the governance process. It is useful to periodically review the structure and functions of the committees and to ensure that everyone knows what to expect from them.

\section{Governance board composition}

Effective boards consist of persons who individually have the core values discussed above and collectively have the competencies and dedication required to govern the hospital effectively $[3,4]$. Their composition should be sufficiently diverse and independent to ensure a broad range of perspectives and robust dialogue. Effective boards also have a strong commitment to continuous improvement of board members' knowledge and leadership skills, both individually and collectively.

A board's composition (the skill mix around the table) is a critical determinant of its effectiveness [3]. High performing boards are, among other things, diverse, independent, and highly engaged. Board composition can no longer be left to chance or be simply a matter of intuition. Effective boards not only evaluate the competencies of the individual board members but also how these complement and support those of the Board as a whole. These competencies would include personal/behavioural attributes, such as integrity, respect for others, humility, self-reflection, regard for the hospital's values, culture, and professional norms, and a willingness to challenge others yet work to reach safe compromises over what is practical. Consistently high levels of knowledge among all members of the board and shared commitment to on-going education are cornerstones of effective governance. Effective boards understand that continuous development of their individual and collective capabilities is one of their most basic responsibilities. The board must not only require others to adopt the shared vision of a positive safety culture which aspires to cause no harm to patients, to provide adequate and, where possible, excellent care and a common culture of caring, commitment and compassion, but they must also do so themselves and be seen to do so [2].

\section{The medical physicist's role}

As healthcare delivery systems become more integrated in order to optimise efficiency, governing boards will not only oversee the performance of individual units, but also evaluate whether these units comply with fundamental standards of service and are aligned to optimise system-wide performance.

As healthcare enters an era of reform within fragile economies, where the general public and the many stakeholders are demanding more productivity, quality and safety with less funding, excellence in hospital governance has never been more necessary. Pivotal to this modernisation should be a zero tolerance approach to any service that does not comply with fundamental standards of service.

At times of economic downturn, small hospital departments, such as Medical Physics departments (services), can suffer the most unless they are properly represented. Failure to ensure that Medical Physics departments receive the proper representation will be to the detriment of patient care.

From the above requirements for the board's composition, it is evident that the Medical Physicist fits the description and possesses the required competences and attributes for an ideal hospital governance board member [5]. The membership of the
Medical Physicist of the hospital governance board is undisputedly essential for the overall good of the patient as the Medical Physicist's extensive knowledge of medical device technology and safety from radiation and other physical agents (including associated European and national legislation), will help ensure the development of policies consonant with the effective, safe and efficient use of expensive resources. It is also essential that Medical Physicists themselves engage in the hospital's governing board's committees.

Currently the involvement of Medical Physicists in the governance of their hospitals is limited as was evident from a short survey carried out by EFOMP in 2013 among its National Member Organisations the results of which are shown below. They are mainly involved in risk and quality management primarily in relation to patient safety and radiation protection. Occasionally are asked to provide technical and scientific support for the renewal of high technology equipment, but often they are not officially included in any governance bodies.

\section{Aims and objectives}

The aim of this policy statement is to encourage Medical Physicists to:

a) Seek appointment on their hospital's governance board.

b) Participate actively in their hospital's governance board committees.

c) Promote the Medical Physics profession to their hospital's governance board and its committees.

\section{Recommendations}

All National Member Organisations should encourage their Medical Physicists to be closely involved in hospital governance and, where this has not already happened, to seek membership of their hospital's governance boards and its committees, emphasising the importance of such membership for the good of the patient and the hospital as a whole.

\section{Summary}

The Guidelines present a background to hospital governance and highlight the importance of the involvement of Medical Physicists in their hospital's governance board and its committees. Medical Physicists, by virtue of their training, have the necessary skills and competences to make important contributions.

EFOMP recommends that National Member Organisations encourage their Medical Physicists to be closely involved in hospital governance and, where this has not already happened, to seek membership of their hospital's governance boards and its committees, emphasising the importance of such membership for the good of the patients and the hospital as a whole.

\section{Acknowledgements}

The Authors acknowledge the help of the EFOMP Officers in compiling this Policy Statement.

\section{References}

[1] Arnwine Don L. Effective governance: the roles and responsibilities of board members. Proc (Bayl Univ Med Cent January 2002;15(1):19-22.

[2] Report of the mid staffordshire NHS foundation trust Public inquiryvol. 3. London: The Stationery Office; 2013. 
[3] Alliance for advancing non profit health care, "Great governance: a practical guide for busy board leaders and executives of non profit healthcare organisations", http://www.nonprofithealthcare.org/resources/governance.asp.

[4] Prybil Lawrence, Levey Samuel, Killian Rex, Fardo David, Chait Richard, Bardach David, et al. Governance in large non-profit health systems: current profile and emerging patterns. Commonwealth Centre for governance Studies, Inc.; 2012.

[5] EC RP Report 174 “Guidelines on medical physics expert”, http://ec.europa.eu/ energy/nuclear/radiation_protection/doc/publication/174.pdf. 